\title{
Traduire
}

Une eutre perspective sur la tratuction

Revue française de la traduction

$242 \mid 2020$

Passons au vert

\section{Lexique de droit administratif franco-croate de Marc Gjidara et Bosiljka Britvić Vetma}

\section{Maja Cioni}

\section{(2) OpenEdition}

1 Journals

Édition électronique

URL : http://journals.openedition.org/traduire/2067

DOI : 10.4000/traduire.2067

ISSN : 2272-9992

Éditeur

Société française des traducteurs

\section{Édition imprimée}

Date de publication : 30 juin 2020

Pagination : 139-141

ISSN : 0395-773X

\section{Référence électronique}

Maja Cioni, « Lexique de droit administratif franco-croate de Marc Gjidara et Bosiljka Britvić Vetma »,

Traduire [En ligne], 242 | 2020, mis en ligne le 15 juillet 2020, consulté le 22 décembre 2020. URL

http://journals.openedition.org/traduire/2067 ; DOI : https://doi.org/10.4000/traduire.2067 


\section{Lu pour vous}

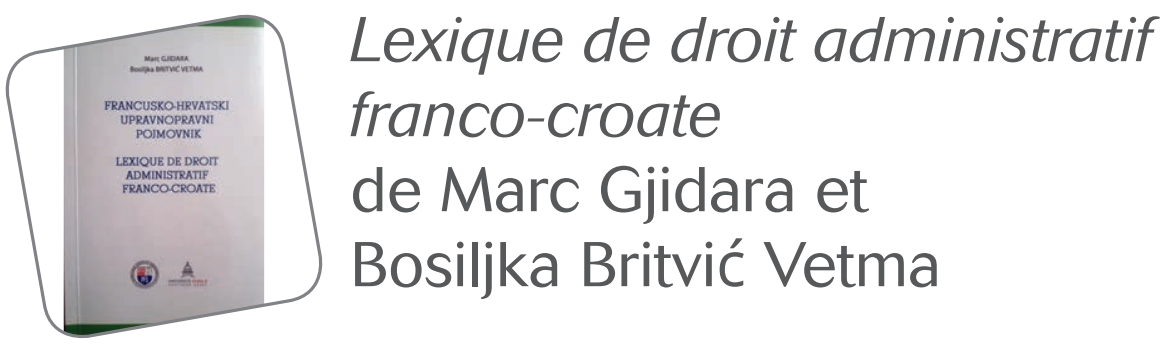

Maja Cioni

Quand la première version du Lexique de droit administratif franco-croate a vu le jour, en 2016, ce n'était qu'une publication modeste. Néanmoins, ce petit ouvrage était déjà le fruit d'une longue collaboration entre le professeur émérite de l'université Panthéon-Assas, Marc Gidara, et sa collègue croate de la faculté de droit à Split, la professeure Bosiljka Britvić-Vetma. Avec le temps, ce glossaire a fait son chemin et trouvé sa place sur les bureaux des étudiants en droit, traducteurs et interprètes, juristes, avocats, magistrats, hauts fonctionnaires, diplomates et députés en poste à Strasbourg, à Bruxelles ou au Luxembourg. Et puis, alors que la matière lexicale continuait à s'étoffer, les auteurs ont choisi d'en publier une deuxième version.

Tout d'abord, la partie proprement terminologique a été enrichie, puis, à la demande d'éminents collègues croates spécialistes du droit administratif, une version bilingue de textes fondamentaux pour cette discipline, tant en Croatie qu'en France, y a été ajoutée. II s'agit d'une part des deux lois croates sur la procédure administrative générale et le contentieux administratif, et d'autre part, pour la France, d'extraits pertinents du Code des relations entre le public et 
l'administration et du Code de justice administrative. Cette initiative s'insère elle-même dans le cadre des "Journées juridiques et administratives franco-croates de Split», rencontres organisées chaque année depuis 2007 afin de faciliter les échanges entre les juristes des deux pays.

Cette réédition élargie a été présentée dans les locaux de l'ambassade de Croatie à Paris, le 9 mai 2019. Le dictionnaire est composé d'un glossaire bilingue où la terminologie juridique française, dans l'ordre alphabétique, est suivie soit par sa traduction croate, soit par une explication en cas d'absence dans le vocabulaire juridique croate. Ainsi, en face d'Abrogation, on peut lire Poništenje, et ensuite poništenje o pćeg propisa ili individualne mjere od strane javnopravnoga tijela (abrogation d'un règlement général ou d'une mesure individuelle de la part d'une institution de droit public). En outre, plusieurs textes juridiques sont proposés dans l'annexe, en croate et en français. Ces documents offrent une source richissime de solutions linguistiques que l'on peut maintenant utiliser en toute sécurité.

Les personnes confrontées dans leur travail quotidien à des problèmes de traduction, notamment de textes et de documents officiels, connaissent le grand manque de dictionnaires spécifiques franco-croates. Comment traduire, par exemple, prekršajni sud? La première proposition serait, bien sûr, tribunal correctionnel. Pourtant ce n'est pas devant cette instance que les contraventions sont jugées. En France, les contraventions relèvent du tribunal de police, tandis que le tribunal correctionnel juge les délits (krivično djelo, zločin).

Le fait est qu'il existe de très nombreux dictionnaires professionnels anglo-croates, mais relativement peu d'équivalents français. La raison en est que de nombreuses disciplines ont été anglicisées rapidement après la guerre d'indépendance (1990-1995), y compris le droit. Cependant, il n'a pas été tenu compte du fait que le droit croate appartient plutôt au système de droit continental, romano-germanique, un système juridique radicalement différent de la Common Law anglo-saxonne.

Ainsi, ce nouveau Lexique vous aidera à trouver le mot juste quand vous chercherez l'équivalent français pour, par exemple, žalba, qui peut être traduit par les termes français recours, plainte, appel, grief, réclamation ou encore doléance. 
L'expression prethodno pitanje constitue un autre cas typique. La traduction adéquate sera question préalable ou question préjudicielle, en fonction du contexte.

Gjidara Marc \& Britvić Vetma Bosilijka, Francusko-hrvatski upravnopravni pojmovnik - Lexique de droit administratif francocroate, Split/Paris, Pravni fakultet Sveučilišta u Splitu et université Paris II Panthéon-Assas, 2018, wWw. Webknjizara.hr (250 kunas, env. 30 euros). 